\title{
Learning to Read: A Problem for Adam Smith and a Solution from Jane Austen
}

\author{
Lauren Kopajtic
}

\section{Introduction}

In the final pages of his Theory of Moral Sentiments (TMS), Adam Smith claims that "the desire of being believed, the desire of persuading, of leading and directing other people, seems to be one of the strongest of all our natural desires" (VII.iv.25). ${ }^{1}$ He connects this desire to the value of "frankness and openness," both of which "conciliate confidence." And he contrasts the qualities of frankness and openness with "reserve and concealment," which "call forth diffidence." "We are afraid," Smith adds, "to follow the man who is going we do not know where" (VII.iv.28). Reserve and concealment are qualities that disappoint and rebuff curious spectators. In his strongest remark, Smith claims that the person of reserve "wraps himself up in impenetrable obscurity ... [and builds] a

L. Kopajtic $(\varangle)$

Fordham University, New York, NY, USA

e-mail: lkopajtic@fordham.edu 
wall about his breast. We run forward to get within it, with all the eagerness of harmless curiosity; and feel ourselves all at once pushed back with the rudest and most offensive violence" (VII.iv.28).

Appearing where they do, in the closing pages of TMS, these remarks have occasioned little scholarly commentary, but they should give us serious pause. Smith is suggesting that the reserved person obstructs the efforts of spectators (VII.iv.28). This is a significant offense because Smith's sympathy-based sentimentalist philosophy requires that spectators be able to read and interpret the situations of agents, discerning with an adequate degree of accuracy what they are feeling and why they are feeling what they feel. But just how different is the reserved person from the self-commanded person, who receives so much praise throughout TMS? And if self-command is like reserve, won't it too block spectatorship?

This chapter finds and examines a serious tension at the center of Smith's moral psychology. Specifically, if self-command is like reserve, then the two basic "efforts" in Smith's moral psychology-the effort of the spectator to sympathetically enter into the feelings of the agent, and the effort of the agent to moderate his feelings-will be in tension (I.i.5.1). While the spectator is trying to sympathetically imagine the agent's situation and enter into his feelings, the agent will be trying to alter what he appears to feel by controlling the expressions of those emotions. This tension leads to a problem-it looks like the agent will thus block and mislead the efforts of the spectator, turning a sympathetic interaction which is supposed to be harmonious and mutually pleasing into something adversarial. Given that most passions require some moderation before the spectator can sympathize with them, it is thus difficult to see how spectators could develop into "impartial and well-informed" observers of most situations (VII.ii.1.49, emphasis added).

These problems only arise if Smithian self-command is like reserve and showing this is the task of the first part of this chapter. After situating and examining the difficulties of Smithian spectatorship, in the second part, I take some steps toward resolving them. I first emphasize a crucial but easily missed feature of Smith's moral psychology, that Smith's model spectators are skilled readers of the people around them. I then consider 
how Smith's moral psychology might have been informed by literary techniques and forms, specifically, eighteenth-century developments in the novel. I focus on Jane Austen's Sense and Sensibility, both because this novel distills and perfects the relevant developments in literary form, and because it is concerned with the same phenomenon found in Smiththe difficulties of spectatorship in a social world governed by norms of propriety that demand the regular concealment of feeling. ${ }^{2}$ Turning to Austen reveals resources that help us to resolve, at least partially, the problems for spectatorship. I draw out two important techniques, focalization and free indirect style, showing how they enable and encourage spectatorial work and thus contribute to the development of skilled readers. I conclude by returning to Smith, revealing how he is introducing subtle refinements to his descriptions of character, refinements informed by the eighteenth-century developments in literary form that reached their full bloom in Austen's novels.

\section{Spectatorship and Self-Command in Smith's Moral Psychology}

In order to show how the problems outlined in the introduction arise for Smith, we must engage with some of the key elements of his moral psychology. I will begin with a discussion of spectatorship and the sympathetic interaction and then turn to Smith's characterization of selfcommand. I will establish that self-command seems indistinguishable from reserve on Smith's view, showing that even the highest and most exemplary form of self-command involves effortful control of emotional expression. I will then draw out, in detail, the problems sketched above.

Smith is a sentimentalist moral philosopher who holds that sentiment is the foundation for morality and that the standard of propriety for all feelings $s^{3}$ is the approval of a well-informed and impartial spectator. Moral sentiments, the sentiments that serve as the basis for moral judgments, are produced through the sympathetic interaction between an agent and an impartial and well-informed spectator. The sympathetic interaction is made possible by the capacity for sympathy. According to Smith, sympathy is the experience of a "fellow-feeling with any passion 
whatever," produced by the spectator's effort to imaginatively enter into the situation of the agent (I.i.1.5). Smith describes this effort as follows,

[T] he spectator must, first of all, endeavor, as much as he can, to put himself in the situation of the other, and to bring home to himself every little circumstance of distress which can possibly occur to the sufferer. $\mathrm{He}$ must adopt the whole case of his companion with all its minutest incidents; and strive to render as perfect as possible, that imaginary change of situation upon which his sympathy is founded. (I.i.4.6)

Upon this effort of imaginative transposition, the spectator will feel a "sympathetic emotion" (I.i.3.1), which is what the agent "should be" feeling, given the situation they are in (I.i.1.4). But the spectator will also compare what the agent should be feeling with what the agent appears to be feeling, which Smith calls their "original passion" (I.i.3.1). This comparison results in a further feeling, a feeling of approval, if the two are in harmony, or disapproval if they are not. This final feeling is what is properly called a moral sentiment.

Smith uses two evaluative terms to describe good spectatorship-good spectators are impartial to everyone involved in the situation, and they are well-informed about the situation (e.g. VII.ii.1.49). My focus is on the second of these two criteria, the standard of good information. How does the spectator gather this information, and what would count as meeting this standard? Smith's discussion of an important limitation on our access to the feelings of others helps to answer this question. Smith writes,

As we have no immediate experience of what other men feel, we can form no idea of the manner in which they are affected, but by conceiving what we ourselves should feel in the like situation. Though our brother is upon the rack, as long as we ourselves are at our ease, our senses will never inform us of what he suffers. They never did, they never can, carry us beyond our own person, and it is by the imagination only that we can form any conception of what are his sensations. Neither can that faculty help us in any other way, than by representing to us what would be our own, if we were in his case. It is the impressions of our own senses only, not those of his, which our imaginations copy. (I.i.1.2) 
Smith acknowledges that we are limited in our ability to sympathetically imagine the minds and feelings of other people, and he suggests that in order to imagine our way into the minds of others, we need to have enough material ("impressions of our own senses") to recreate a plausible version of what they feel. ${ }^{4}$

The spectator will be starting from her own perspective, limited to using her own senses and imagination as she tries to gather information about the agent's situation and imaginatively change her situation to that of the agent. As Smith says in the passage quoted above, this will involve "adopt[ing] the whole case" of the agent and "bring[ing] home every little circumstance" of the feeling in question (I.i.4.6). This focus on the situation of the agent is one of Smith's important refinements to sympathy. For Smith, the situation of the agent comprises the set of factors which cause him to feel as he feels, and which would explain why he feels as he feels. Such factors could include his immediate environment, his relationships with others involved in the situation, his beliefs, intentions, and emotions, his personality and character traits, and so on. This focus on situation means that, for Smith, sympathy is not merely the result of a contagion of feeling. A spectator does not simply "catch" joy upon seeing an agent's smiling face-she may automatically feel something upon observing that expression, but she will also attempt to imaginatively reconstruct the circumstances of the agent's smiling face. Gathering information about the agent's situation is thus crucial to good spectatorship because it enables the imaginative transposition required for sympathizing.

Focusing on the spectator's side of the sympathetic interaction, as described in the early pages of TMS, we find a social world populated with curious, caring, and careful observers. Spectators are described as wanting to sympathize with agents, as striving to be sensitive to agents' particular situations, and as aiming at understanding and mutual sympathy (I.i.2). Later in TMS, Smith stresses that the work of good spectatorship is that of a lifetime. Good information about the sentiments and opinions of other people is achieved through the "slow, gradual, and progressive" work of making "observations upon the character and conduct both of [oneself] and of other people" (VI.iii.25). Smith is aware, of course, that actual people will struggle to meet the 
standard of good spectatorship most of the time-being distracted, preoccupied, or biased (I.i.3.4)—but he claims that the sentiments of the well-informed and impartial spectator are nonetheless the "precise and distinct measure by which [the] fitness or propriety of affection can be ascertained or judged of" (VII.ii.1.49). The sentiments of the wellinformed and impartial spectator set the standard for propriety in all feelings and affections.

This depiction of spectatorship becomes more complicated when we examine the agent's side of the sympathetic interaction. According to Smith, we are thrown into the world of sympathy and spectatorship at a young age, and we soon learn that others will not feel for our own passions and interests as we do (III.3.22). Because of this, and because agents want the sympathy and approval of spectators, Smith says, agents must regulate their feelings, bringing them to the level into which an impartial spectator could enter. Smith describes the effort of the agent as follows:

The [spectator's] thought of their own safety, the thought that they themselves are not really the sufferers, continually intrudes itself upon them; and though it does not hinder them from conceiving a passion somewhat analogous to what is felt by the sufferer, hinders them from conceiving any thing that approaches to the same degree of violence. The person principally concerned is sensible of this, and at the same time passionately desires a more complete sympathy. ... But he can only hope to obtain this by lowering his passion to that pitch, in which the spectators are capable of going along with him. (I.i.4.7)

The effort of self-command, as described here, is that of moderating one's emotions so that they harmonize with the anticipated sentiments of the spectator. ${ }^{5}$

On Smith's account, self-command is the task of the agent who seeks sympathy, and it is an effort impressed upon most of us most of the time. This demand for consistent self-command is explained by the difficulty that spectators have in sympathizing with most types of passions. Smith sorts the passions into five main classes: bodily passions (e.g. hunger, pain, etc.), peculiar passions, or passions that derive from a peculiar turn of an agent's imagination (e.g. romantic love), selfish passions (e.g. grief and 
joy upon private misfortune or fortune), unsocial passions (e.g. hatred and resentment), and social passions (e.g. generosity, kindness). Smith argues that spectators find it very difficult to sympathize with the originally felt degrees of the selfish passions, and that they cannot sympathize with most degrees of the bodily or the peculiar passions because all three classes are too close to the agent's own interests and too difficult for someone else to imagine their way into. Spectators find it difficult to sympathize with the unsocial passions because they are so distressing and because the spectator's sympathy is often divided between the person feeling hatred and the person hated. Only the social passions tend to be easy for spectators to immediately sympathize with, such that an agent could likely immediately express their original passion without some attempt at self-command. But in all other cases, the desire for the spectator's sympathy will lead the agent to modify her original passion. ${ }^{6}$

As described thus far, self-command involves moderating one's feelings so that they would be approved of by the well-informed and impartial spectator. But what does this effort of self-command look like in action? And, to return to the question raised in the introduction, is self-command like reserve?

To answer these questions, I want to examine a series of vignettes from Smith's discussion of how we learn to command our feelings (III.3.2125). Smith begins by drawing the character of "the weakest man" while he suffers a personal misfortune (III.3.23). At first, this person is calmed by the presence of a spectator, being "immediately impressed," in an almost "mechanical[]" way, with the view that this spectator would take of his miserable situation (III.3.23). But very quickly his own partial view returns and he "abandons himself, as before, to sighs and tears and lamentations; and endeavours, like a child who has not yet gone to school, to produce some sort of harmony between his own grief and the compassion of the spectator, not by moderating the former, but by importunately calling upon the latter" (III.3.23). The weakest man cannot impose restraint on his passions and so he importunes the spectator to carry the burden of the sympathetic interaction.

The next portrait Smith paints is of the "man of a little more firmness," who tries more intentionally to keep the view that the spectator would take of his situation in sight. Smith writes, 
In most cases he avoids mentioning his own misfortune... He endeavours to entertain [his company], in his usual way, upon indifferent subjects, or, if he feels himself strong enough to venture to mention his misfortune, he endeavours to talk of it as, he thinks, they are capable of talking of it, and even to feel it no further than they are capable of feeling it. If he has not, however, been well inured to the hard discipline of self-command, he soon grows weary of this restraint. A long visit fatigues him; and, towards the end of it, he is constantly in danger of doing, what he never fails to do the moment it is over, of abandoning himself to all the weakness of excessive sorrow. (III.3.24)

Again, Smith is describing someone who is suffering from a private misfortune, and he describes the temporarily successful self-command of this person as amounting to avoiding the subject of his excessive sorrow. In comparison with these two previous characters, the third character, the "man of real constancy and firmness," maintains composure and command in all situations:

The man of real constancy and firmness, the wise and just man who has been thoroughly bred in the great school of self-command ... maintains this control of his passive feelings upon all occasions; and whether in solitude or in society, wears nearly the same countenance, and is affected very nearly in the same manner. In success and in disappointment, in prosperity and in adversity, before friends and before enemies, he has often been under the necessity of supporting this manhood ... He has been in the constant practice, and, indeed, under the constant necessity, of modelling, or of endeavouring to model, not only his outward conduct and behaviour, but, as much as he can, even his inward sentiments and feelings, according to those of this awful and respectable judge. He does not merely affect the sentiments of the impartial spectator. He really adopts them. (III.3.25, emphases added)

This portrait provides an instructive depiction of near-perfect selfcommand. This figure maintains control of his feelings at all times and wears "nearly the same countenance" in all situations. He is not unfeeling or insensible, but he strives, with a great deal of success, to act and feel only as an impartial spectator would, and he models his outward conduct and behavior entirely upon the impartial spectator. 
These three portraits reveal that while virtuous self-command aims at the actual alteration of feeling-bringing the exterior expression in line with the interior feeling-developing or "work-in-progress" selfcommand almost always takes the form of concealing or feigning feeling. ${ }^{7}$ The "weakest man" cannot keep up the appearance of anything but what he actually feels, and he expresses his distress without restraint or alteration. The "man of a little more firmness" is trying to keep his company from seeing the distress he feels as he struggles to bring that distress down from its improper level. But his mask is in constant danger of slipping, and when it does, the feelings he expresses will be excessive and improper. The "man of real constancy and firmness" wears the same countenance at all times. But Smith writes that this character models "not only his outward conduct and behaviour, but, as much as he can, even his inward sentiments and feelings" after the impartial spectator's, suggesting with that contrastive phrasing that even at this high level of self-command, much of this person's effort is focused on controlling the expressions of feeling (III.3.25, emphasis added). Indeed, it is the weakest man who is the most open about what he feels; both the man of middling firmness and the man of real firmness are hiding or feigning their feelings.

Smithian self-command thus seems to involve concealment and perhaps also dissimulation, but Smith does not seem concerned that this amounts to hypocrisy or blameworthy deception. ${ }^{8}$ Nor does he seem concerned that his exemplar of self-command seems to be indistinguishable from the cold and reserved character he criticizes elsewhere. As we saw above, Smith describes the person of "reserve and concealment" as someone who "disappoint[s] the curiosity" of spectators, cautiously keeping his opinions and sentiments a secret (VII.iv.28). And in his discussion of the influence of custom on the moral sentiments, Smith associates "civilized nations" with sympathy, free expression of emotion, frankness, openness, and sincerity, while "savage and barbarous nations" are characterized by reserve, concealment of emotion, insensibility, falsehood, and deception (V.2.8-11). Smith's explanation of these differences is that the living conditions of each kind of nation are different enough that the levels of propriety for the various emotions are different. In the 
conditions of poverty, danger, and insecurity, which is how Smith characterizes "barbarous and savage nations," a person "expects no sympathy from those about him" (V.2.9). It is too difficult to feel for others when one's own misery "pinches" so severely (V.2.9). Expecting no sympathy from the spectator, the "savage" must exert an extreme degree of selfcommand, completely hiding his passions from all onlookers. Smith writes, "His passions, how furious and violent soever, are never permitted to disturb the serenity of his countenance or the composure of his conduct and behavior" (V.2.9). ${ }^{9}$ We might well be reminded of Smith's description of the "man of real constancy and firmness," who always "wears nearly the same countenance" (III.3.25).

Smith's description of the self-commanded "savage" is ambivalent. ${ }^{10}$ He seems to admire the "heroic and unconquerable firmness" and the "magnanimity and self-command" which is so strong as to be "almost beyond the conception of Europeans" (V.2.9-10). But he also links this extreme self-command to deception, writing that "barbarians ... being obliged to smother and conceal the appearance of every passion, necessarily acquire the habits of falsehood and deception" (V.2.11). Selfcommand, requiring the concealment of feeling, tends toward falsehood and deception. These remarks about self-command occur in Smith's discussion of the influence of custom on our moral sentiments, and the extreme nature of the self-command found in "savage" nations is explained by the conditions of life in those nations. But Smith is describing the varying forms of universal propensities and capacities of human nature. In impoverished and insecure situations, self-command over-develops, leaving no room for openness and expression, and the vulnerability that comes along with these. But even in conditions of abundance and ease, self-command will involve concealing feeling. This is because self-command is the effort of moderating one's emotions so as to achieve the sympathy of a well-informed and impartial spectator. And even in the easiest and most open societies spectators will find some passions difficult to sympathize with. In Smith's three vignettes of selfcommand, the men in question are all clearly of "humane and polished nations," and they are all clearly trying to hide an emotion that the impartial spectator would not be able to enter into. 
Let's bring the spectator back into our discussion. When we considered the work of spectatorship above we found that good spectators were curious, caring, and careful. A good spectator tries to imaginatively recreate an agent's situation, gathering information about that situation in her attempt to change her situation and feel as the agent does. As she does this work, she will feel a sympathetic emotion, which is the feeling the agent should be feeling given the situation he is in. But she will also compare the sympathetic emotion she feels with the agent's original passion. Without this comparison there can be no moral sentiment- the moral sentiment is a separate sentiment felt upon the comparison of the sympathetic emotion and the original passion. ${ }^{11}$ Access to the original passion of the agent is thus crucial at two stages in the spectator's imaginative work: It is an important piece of information about the agent's overall situation, and it is necessary for the comparative work required for the experience of a moral sentiment. This is where we see the problem sketched in the introduction starkly - while the spectator is trying to read the situation for this information, the agent is trying to alter or hide this information by controlling his expressions of emotion. Either the spectator ends up sympathizing with a feigned emotion, resulting in a false moral sentiment, or the spectator has to somehow pry away the mask of self-command, interfering with the agent's efforts. ${ }^{12}$

This tension between the efforts of the spectator and the agent generates a problem. First, as we saw above, most passions require some moderation before the spectator can sympathize with them, even in "humane and polished nations." Thus, some self-command will be required most of the time. Given this state of affairs, it is difficult to see how spectators could develop into well-informed observers of most situations. Smith writes that the work of refining one's sense of propriety is "slow, gradual, and progressive," and he admits that the accuracy, justness, and exactitude of this sense will vary "according to the delicacy and acuteness of that sensibility with which those observations were made, and according to the care and attention employed in making them" (VI.iii.25). But this takes no notice of the fact that those whom one is observing will be regularly concealing and feigning their feelings. Good spectatorship seems threatened by widespread observational inaccuracy. Furthermore, Smith assumes that we can distinguish effortful 
self-command from mere indifference, insensibility, indolence, or apathy, but he does not acknowledge that the self-commanded person will be making this work difficult for us. ${ }^{13}$ To use the example from Smith's discussion of the self-commanded "savage," how could a spectator tell the difference between the person who is effortfully controlling their emotions and presenting the "countenance of serenity," and the person who is genuinely unruffled and presenting the same countenance? It is difficult to see how spectators could learn to distinguish self-masking traits, like self-command, from other, non-virtuous traits. ${ }^{14}$

At this point, a reader might be worried that I am overstating the tension between the efforts of the spectator and agent and the problem that arises from this tension. Smithian spectators are not limited to just the agent's expressions of emotion as they gather information about the agent's situation - they have the entire situation to read and interpret. Put another way, while the emotions of others might not be transparent to spectators, their situations should be, and that should provide enough information to avoid these worries. ${ }^{15}$

I agree that the Smithian spectator will be reading the entire situation of the agent and not just their expressions of emotion. But a spectator who can read a situation, controlling for the agent's possible dissimulation, is already savvy and skilled, and given the obfuscating and falsifying efforts of self-commanded agents, it is not clear how anyone would ever attain such skill. As Charles Griswold writes, "[interpreting a situation] requires ... a discursive description of the situation, as well as a potentially complicated appraisal of what the salient features are ... The 'situation' does not consist simply in a set of facts; it will include, for any spectator however impartial, a judgement of what the relevant facts are, of their causal relations, of how they did or might have seemed to an actor at the time and why" (2010, 68-69, emphasis in original). Furthermore, as Griswold adds, "it may well be not simply a question of the spectator looking at the scene, adjusting the eye of the mind, and sympathetically getting the full picture, so much as listening to the actor's suasive narrative, and then comparing it to his or her own interpretation" (2010, 70). ${ }^{16}$ Griswold is describing how the spectator's interpretive work is 
already highly complex, and I have argued that there's a further complication-the demand for self-command means that agents will be not only trying to persuade, but will be dissembling in order to better persuade.

Smith is not sanguine about the difficulties of spectatorship, but he fails to sufficiently acknowledge the deep problems with assuming that we will be able to imaginatively and accurately grasp the emotions of others. Put another way, while Smith admits, on the first page of TMS, that we cannot assume that the other will be transparent to us, he fails to sufficiently address just how much opacity spectators will be faced with, and he fails to acknowledge that the ethical demands built into his moral psychology will contribute to producing that opacity. So, how can Smith plausibly account for how sensitive, discerning and well-informed spectators develop in a world where the demand for selfcommand requires agents to regularly conceal and feign their feelings? I think there are resources in Smith to respond to this question, but seeing them will require seeing something about Smith's descriptive and rhetorical techniques.

\section{Literature and Learning to Read}

I have argued that there is a tension between the efforts of the spectator and the agent in Smith's moral psychology, and that this tension generates problems for Smith's account of how spectators develop into well-informed observers of human character and conduct. I now contend that Smith can ameliorate this problem by accepting that one of the important ways in which spectators develop their spectatorial skills is by developing their skills as readers of other people. As Griswold has argued, the emphasis on vision and ocular metaphors throughout TMS too readily suggests that the spectator will simply see the situation of the agent, as she sees a scene through a window $(2010,67-68) .{ }^{17}$ But as our close examination of the tension between the efforts of the agent and spectator has revealed, agents will rarely be transparently open to spectators, and discerning what they are feeling will require savvy interpretation of complex clues. The central question of this chapter thus 
shifts from a question about spectatorship to a question about readership: What does good reading of other people look like, and how might it be developed? In order to address these questions, I turn to developments in eighteenth-century literature and to their perfection in the hands of Austen.

First, a comment on spectatorship and training. For Smith, and for any moralist conceiving of moral education as the development of virtuous character traits, moral education will not be achieved through indoctrination or the internalization of a set of rules. And because Smith is a sentimentalist, moral education will involve, especially, developing one's sympathetic imagination and one's ability to occupy the perspective of the well-informed and impartial spectator. Moral education thus involves training or practice and it requires venues for that training. Smith's account of the development of spectatorship emphasizes real-world, quotidian, and often public interactions - the child on the schoolyard, the man on the street, and the person in the company of strangers (III.3.22, I.i.3.4, I.i.4.9). But my contention is that such venues will not be sufficient for the development of well-informed spectators who can read agents engaged in concealing their emotions and moderating their expressions. Special sites, special perspectives, and special tools are required.

But what kind of tools and how are they supposed to work? What is needed is a training ground for spectatorial work, a place for the wouldbe skilled spectator to engage in the advanced tactics of the exemplary spectator, including perspective-switching and sympathetic identification with complex characters. Fortunately, the novel, especially as it was developing in the second half of the eighteenth century (while Smith was revising and re-writing TMS), provides an especially effective site for such training. And in the remainder of this chapter, I will show that there is good reason to think that Smith would have accepted that one way of becoming a good spectator is through engagement with imaginative and narrative depictions of other people. ${ }^{18}$

As an initial piece of support for this reading, we can take a cue from an addition Smith made to the 1790 edition of TMS. Smith writes, "The poets and romance writers, who best paint the refinements and delicacies of love and friendship, and of all the other private and 
domestic affections, Racine and Voltaire; Richardson, Maurivaux [sic], and Riccoboni; are in such cases, much better instructors than Zeno, Chrysippus, or Epictetus" (III.3.14). Smith's claim is that these authors instructively illustrate relationships of love and friendship as well as the "private and domestic affections," like "parental tenderness" and "filial piety," which Smith describes on the previous page (III.3.13). ${ }^{19}$ It is not clear from this remark how literature has this instructive function, but I suggest that Smith's mention of three mid-eighteenth-century prose writers-Samuel Richardson, Pierre de Marivaux, and Marie-Jeanne Riccoboni-can provide us with clues that will lead us to Austen and her techniques.

While much might be said about the three prose writers Smith mentions, I will pull out three well-established and shared features of their works which are relevant to our discussion here. First, all three writers produced narratives detailing, at great length and with minute attention, the inner lives and feelings of their subjects. Richardson's Clarissa (1747-1748), Marivaux's unfinished La Vie de Marianne (17311741) and Riccoboni's Lettres de Milady Juliette Catesby (1759), to take just three examples, are all studies of human feeling, largely as revealed in intimate familial and romantic relationships. The subjects of these novels meditate extensively on the nuances of their own hearts, and they investigate the motives and affections of the people around them. Second, all three writers employ literary forms that purport to convey authentic emotions in an immediate way-that is, they purport to convey the sentiments of an individual as experienced by that individual, often (implausibly) at the moment of experience. ${ }^{20}$ All three employ the epistolary form (in different degrees of development), telling a narrative through a series of private letters to and from specific individuals. Third, and most importantly for our purposes, all three writers contributed to the development of stylistic techniques designed to facilitate sympathetic identification with the subjects of their narratives. This was in part accomplished through the presence of the first two features, for a "more convincing presentation of the inner lives of ... characters and of the complexities of their relationships," allowed for a closer sympathetic identification with those characters (Watt, 200-201). But, at least in the case of Richardson, a case can be made, as Joe Bray does, for a more direct 
contribution. Bray holds that Richardson's epistolary style in Familiar Letters (1741) and Clarissa "move[s] beyond the model of a standard letter" into free indirect style through the omission of speech tags and the integration of direct speech into narrative "without any attributing clause." ${ }^{21}$ Eliding the framing device of the letter or the memoir, either through the use of free indirect style, or through other focalizing techniques, enables the reader to slide more seamlessly into the thoughts and feelings of the subject.

Taking together these three features of the novels of Richardson, Marivaux, and Riccoboni (features that are of course shared by other writers not explicitly mentioned by Smith), we can see that the novel, in the form that would have been familiar to Smith, was in part concerned with rendering the inner life of another person accessible to the reader. ${ }^{22}$ Furthermore, through the stylistic devices designed to convey that inner life in an immediate and apparently unmediated form, these novels could activate the spectatorial apparatus of the reader, bringing them to sympathize with the characters depicted. ${ }^{23}$ In order to see how this works more clearly, let's work through an example. As Barbara Benedict and others have argued, Jane Austen's Sense and Sensibility is a novel that manages to distill many of the themes and concerns of the eighteenth-century sentimentalist novel, while also developing in a masterful way the techniques more or less incipiently present in earlier novels. ${ }^{24}$ Given that this novel also shares the concerns we have been focusing on in TMS - the balance of feeling and self-command and the difficulties faced by spectators when the agents around them are concealing and feigning their emotions-it provides an apt example for our purposes. ${ }^{25}$

Elinor Dashwood is one of two heroines in Austen's Sense and Sensibility, along with her sister, Marianne. When we meet Elinor at the start of the novel, we learn that "Elinor ... possessed a strength of understanding, and coolness of judgment, which qualified her, though only nineteen, to be the counsellor of her mother ... She had an excellent heart; - her disposition was affectionate, and her feelings were strong; but she knew how to govern them" (SS 7). ${ }^{26}$ Elinor's self-command is contrasted with the frequently excessive sensibility of her sister, Marianne, and their mother, Mrs. Dashwood. But in the first volume of the novel, our sense of the value of Elinor's self-command is tempered 
by Marianne's frequent comments on that quality and by Marianne's own ardent and impulsive example. Marianne rightly notices that selfcommand frequently requires one to conceal and feign their feelings, and such pretense is anathema to her: "Marianne abhorred all concealment where no real disgrace could attend unreserve; and to aim at the restraint of sentiments which were not in themselves illaudable, appeared to her not merely an unnecessary effort, but a disgraceful subjection of reason to common-place and mistaken notions" (SS 63-64). To Marianne, selfcommand almost always involves the "disgraceful" and deceitful restraint of one's feelings for the sake of "common-place and mistaken" ideas of propriety and decorum.

In the early chapters of Sense and Sensibility, we see the two sisters on opposite sides of the question of whether one should command one's emotions when doing so requires concealment and dissimulation. As the plot unfolds, this question becomes more complicated. At the end of the first volume, Elinor and Marianne are thrown into regular meetings with the Steele sisters, and with little warning, Elinor is pressed into Lucy Steele's confidence, only to learn that Lucy has been secretly engaged for several years to Elinor's own supposed beloved, Edward Ferrars. This initial conversation between Elinor and Lucy is painful to read, and we repeatedly see Elinor struggling with astonishment and disbelief as Lucy reveals her history, but maintaining her composure nonetheless (SS 152155).

Lucy's undesired information forces Elinor's self-command into an even higher gear. The promise to keep Lucy's information a secret, combined with Elinor's general disposition for self-command and caution, leads her to regularly feign indifference and composure, and to screen her feelings from others. ${ }^{27}$ Through her efforts at concealing her feelings, Elinor convinces her own mother and sister that she is unaffected by the loss of Edward to Lucy, and it is not until the very end of the novel, when Edward is free again to marry Elinor, that they realize her efforts. In a poignant moment, we watch as Mrs. Dashwood finally realizes how Elinor has suffered: 
She now found that she had erred in relying on Elinor's representation of herself ... She found that she had been misled by the careful, the considerate attention of her daughter, to think the attachment, which once she had so well understood, much slighter in reality, than she had been wont to believe, or than it was now proved to be. She feared that under this persuasion she had been unjust, inattentive, nay, almost unkind, to her Elinor; that Marianne's affliction, because more acknowledged, more immediately before her, had too much engrossed her tenderness, and led her away to forget that in Elinor she might have a daughter suffering almost as much, certainly with less self-provocation, and greater fortitude. (SS 402-403)

Mrs. Dashwood's thoughts in this moment help us to see how the selfcommanded person blocks and misleads her spectators. Even a spectator like Mrs. Dashwood, with an ardent heart and extensive information about the agent, may fail to discern the feelings and efforts of the highly self-commanded person. This is because the self-commanded person represents herself as feeling less than she does. How she feels and how she appears to feel come apart because of her very efforts. ${ }^{28}$

But notice that as readers we see more than Mrs. Dashwood, Marianne, or any other character in Elinor's world could see. Compared with Austen's characterization of a different reserved character-Jane Fairfax in Emma, for example-the reader is not blocked from understanding Elinor by the reserve she presents to others, nor is the reader led to see her as suspiciously concealing some desirable information. ${ }^{29}$ Instead, Austen gives the reader what we might call a bi-focal view of self-command. We see Elinor's composure of face and voice as presented to Lucy Steele while we sympathize with the shock and astonishment that Elinor is feeling; we watch Elinor's easy manner with her family while knowing of the efforts she has made to command her disappointment about Lucy's unwelcome information. In Austen's depiction of Elinor Dashwood, we are afforded a much fuller understanding of another person than we can expect to gather from mere observation of behavior. This fuller understanding of the self-commanded person is accomplished in part through Austen's use of focalized narrative, positioning the reader so that they share Elinor's perspective, and also through Austen's use of free indirect style, which seamlessly merges character and narrator and then moves them apart. 
Focalization and free indirect style help the reader to inhabit a perspective other than her own, potentially enabling her to sympathize with and understand sentiments and opinions other than her own. ${ }^{30}$

To see more concretely how focalization and free indirect discourse enable spectatorial work, let's take an example from early in Sense and Sensibility. Edward is visiting the Dashwood women and he arrives wearing a new ring, into which a lock of hair is set. Marianne immediately comments on this ring, speculating that the hair must belong to Fanny, Edward's sister, even though it appears to be of too light a shade. Edward responds with embarrassment, glances at Elinor, and confirms that it is Fanny's hair. Austen then takes us inside Elinor's mind as she reacts to the exchange:

Elinor had met his eye, and looked conscious likewise. That the hair was her own, she instantaneously felt as well satisfied as Marianne; the only difference in their conclusions was, that what Marianne considered as a free gift from her sister, Elinor was conscious must have been procured by some theft or contrivance unknown to herself. She was not in a humour, however, to regard it as an affront, and affecting to take no notice of what passed, by instantly talking of something else, she internally resolved henceforward to catch every opportunity of eyeing the hair and of satisfying herself, beyond all doubt, that it was exactly the shade of her own. (SS 114)

When we read this we are, of course, as much in the dark about the former possessor of the lock of hair as are Marianne and Elinor. Through focalization and free indirect discourse, though, we are brought to make the same inference that Elinor does-that Edward somehow acquired a lock of Elinor's hair and set it into a ring. And we are encouraged to feel as Elinor does about this information-hopeful and excited.

Of course, the hair is not Elinor's but Lucy Steele's, and upon rereading this passage with the full set of facts in mind, it is striking how quickly Elinor jumps to the conclusion that "it was exactly the shade of her own," despite the very compelling fact that she does not know how Edward could have gotten it. Elinor is misled by wishful thinking, and the reader is misled with Elinor, so when Lucy reveals that it is her hair, we are astonished and mortified with Elinor. Focalization and free 
indirect discourse engage the reader's spectatorial apparatus, bringing the reader to switch perspectives, to read for cues and information, to sympathize with one or more of the persons involved, and to feel sentimental reactions to the construed situation.

Austen's depiction of Elinor Dashwood affords the reader privileged access to another mind. This alone would provide a special venue for spectatorial work, allowing the reader to be exceedingly well-informed about someone else and therefore to make accurate and precise judgments about them. But Austen's use of focalization and free indirect discourse accomplish further special work, bringing the reader through the movements of spectatorship. These techniques can be used to produce the work of good spectatorship, but they can also be used to produce flawed spectatorship. When we are brought to make a mistake with Elinor, and then to confront that mistake, we learn that even an excellent judge like Elinor is fallible, and perhaps also that we, with our apparently privileged perspective, can be fallible too. Of course, this requires a careful reader who is willing to re-read, but so does Smithian spectatorship.

How might these literary techniques and resources ameliorate the problem that we found in Smith? Given that self-commanded people will be concealing their feelings and their efforts of self-command, Smith owes us an account of how anyone could develop into a skilled spectator. Using the example of Austen and other eighteenth-century novels, I have tried to show that engagement with a specific kind of literature-literature that activates the reader's spectatorial apparatus - should be part of the Smithian spectator's training and development. To conclude, I want to return to Smith to see how much of this might be already in his account of spectatorship, and to consider how far this account gets us.

Returning to Smith's three vignettes of self-command after this extended tour through Austen's masterful illustrations of character reveals just how illustrative Smith's own prose can be. As he unfolds the character of each of these figures, Smith moves between descriptions of their behavior and conduct as it would look to an outside observer and descriptions of their feelings and thoughts. Indeed, TMS abounds with such bi-focal illustrations of outward behavior and inward emotion. In a 
passage from early in TMS, Smith writes that we "are disgusted with that clamorous grief, which, without any delicacy, calls upon our compassion with sighs and tears and importunate lamentations. But we reverence that reserved, that silent and majestic sorrow, which discovers itself only in the swelling of the eyes, in the quivering of the lips and cheeks, and in the distant, but affecting, coldness of the whole behavior" (I.i.5.3). In this passage, Smith, like Austen, is giving us a bi-focal view of this instance of self-command, allowing us to see both the mask of reserve and the feeling beneath. He implies that a "silent and majestic sorrow" can be "discover[ed]" in certain tells of the countenance-swelling eyes, quivering lips and cheeks, cold behavior. It is because we can see both the efforts and effects of self-command and know the feeling that is being commanded that we regard this figure with "respectful attention" (I.i.5.3). But this bi-focal view is given to us by Smith, and we are directed explicitly to the minute expressions and told what they mean.

Smith does not dwell on the characters he describes, and so his technique cannot produce the same insight and understanding that Austen's does, but he does describe those characters with care and sensitivity. Throughout Smith's TMS, argumentative and philosophical prose is leavened with vivid sketches of different characters-from the man stung by his guilty conscience (III.2.9), to the "poor man's son" who is cursed with ambition (IV.1.8), to the "savage" who faces his enemies with "serenity" and "composure" (V.2.9). ${ }^{31}$ These illustrations bring to life both the outer appearance and conduct of the character and the sentiments and thoughts that animate him. And it is these illustrations, and those we can find in literature, that help ameliorate the philosophical problem with which we have been concerned. In a world where concealment of feeling is not only unavoidable but also morally and socially demanded of us, our task as spectators is to observe as widely as we can the character and conduct of others. With traits like self-command, our observations "in the field" will likely not be sufficient because of the self-masking quality of this trait. But if we supplement our fieldwork with sustained engagement with narrative and imaginative illustrations of other minds and other characters, we may become more discerning spectators.

But I do not want to overstate this point. The problem facing Smith's moral psychology is a deep one. The minds of others are not transparent 
to us, and we will always be interpreting their character and conduct from situated and imperfect starting points. Literature can provide a controlled space where we can practice our spectatorial skills from a special standpoint, with artificially good information, with the freedom to make mistakes and learn from them, and with the ability to re-read with a fuller sense of the situation in mind. But this practice and training will not be simply transferable to the public, real-world settings for spectatorship. I will be a poor spectator of my self-controlled and prudent sister, for example, if I assume that reading Sense and Sensibility will give me immediate insight into what her inner life is like. A better lesson to draw from my engagement with that novel is that I might fail to understand my much-loved sister because there are certain things that she cannot share with me. Perhaps I learn the lesson that Marianne and Mrs. Dashwood learn-that the self-commanded person may not reveal herself to me-and I learn to be cautious in my judgments of coldness and suspicious reserve.

\section{Conclusion}

In this chapter, I have articulated and explored the problem of how sensitive, discerning, and well-informed spectators can develop in a world where the demand for self-command requires agents to regularly conceal and feign their feelings. Bringing Smith and Austen into dialogue on this problem reveals a way out. Spectators may indeed be faced with the challenge of discerning traits like self-command, but there are resources available to assist that work (although not to make it easy). We can train our spectatorial skills through engagement with complex, psychologically rich literature, like Austen's novels. Indeed, as I have shown, Smith seems to be importing the techniques of the novelist into his own philosophical prose. Techniques like focalization and free indirect discourse allow an author, whether of a philosophical or a literary text, to lay open to a reader the workings of a trait that tries to resist and redirect interpretation. They help us to see the mask worn by the self-commanded person while also feeling the emotion that seethes beneath that mask. ${ }^{32}$ 


\section{Notes}

1. Unless otherwise noted, all references to Smith are to Adam Smith, The Theory of Moral Sentiments, eds. D.D. Raphael and A.L. Macfie (Liberty Fund, 1982), abbreviated as TMS. Throughout this chapter, I cite TMS in the manner recommended by the Adam Smith Review, referring to part, section, chapter, and paragraph.

2. Why Austen? I partly address this question below, but a full discussion would require much more space than I have here. Briefly, while it has not been decisively shown to what extent Austen directly knew of the philosophical writings of Smith, several scholars have argued for her familiarity with Hume and Smith as well other British moralists. For further arguments connecting Austen's thought to that of Hume, Smith, and British Enlightenment thinkers in general, see: Christel Fricke, "The Challenges of Pride and Prejudice: Adam Smith and Jane Austen on Moral Education," Revue internationale de philosophie, 269 (2014), 343-372; Rae Greiner, Sympathetic Realism in Nineteenth-Century British Fiction (Johns Hopkins University Press, 2012); Hina Nazar, Enlightened Sentiments: Judgment and Autonomy in the Age of Sensibility (Fordham University Press, 2012); Charles R. Pigden, "A 'Sensible Knave'? Hume, Jane Austen and Mr Elliot," Intellectual History Review, 22:3 (2012), 465-480; Karen Valihora, Austen's Oughts: Judgment after Locke and Shaftesbury (University of Delaware Press, 2010); E.M. Dadlez, Mirrors to One Another: Emotion and Value in Jane Austen and David Hume (Wiley-Blackwell, 2009); Peter Knox-Shaw, Jane Austen and the Enlightenment (Cambridge University Press, 2004); Elsie B. Michie, "Austen's Powers: Engaging with Adam Smith in Debates About Wealth and Virtue," Novel: A Forum on Fiction, 34:1 (2000), 527; Kenneth L. Moler, Jane Austen's Art of Allusion (University of Nebraska Press, 1968), and "The Bennet Girls and Adam Smith on Vanity and Pride," Philological Quarterly, 46 (1967), 567-569.

3. I use the term "feeling" throughout this chapter as the broadest term for affective states. Smith does not offer a careful delineation of this class, moving between terms like "feeling," "passion," "affect," and "sentiment" without differentiation. 
4. See Samuel Fleischacker, Being Me Being You: Adam Smith and Empathy (University of Chicago Press, 2019), 17-19 for a critical discussion of Smith's argument here, which is fairly obviously meant to target David Hume's account of sympathy in A Treatise of Human Nature. Fleischacker claims that this is "a bad argument" (16), stemming from Smith's holding "a private access model of the mind" (17). See also Fleischacker, "Sympathy in Hume and Smith: A Contrast, Critique, and Reconstruction," in Intersubjectivity and Objectivity in Adam Smith and Edmund Husserl, edited by C. Fricke and D. Føllesdal, (Frankfurt: Ontos, 2012), 273-312. This earlier paper recognizes a version of the problem I am exploring here, noticing that Smith's claim that the spectator compares their "sympathetic emotion" with the "original passion" of the agent requires that we can get some idea of the "original passion" of the agent from their expressions. I discuss this issue below.

5. As I argue elsewhere, Smithian self-command is a sentimental as opposed to a rational effort, which involves the agent taking up the perspective of a well-informed and impartial spectator on her own original passions, feeling a sympathetic emotion and a moral sentiment in response, and then using that moral sentiment (approval or disapproval) as a guide in altering her original passion. See Lauren Kopajtic, "Adam Smith's Sentimentalist Conception of Self-Command," Adam Smith Review, 12 (2020), 7-27.

6. Smith's discussion of the level of propriety for each of these passions is focused on the level of proper expression. In his opening remarks he classifies passions into two groups, "passions which it is indecent to express very strongly," and those "which the strongest expressions are upon many occasions extremely graceful" (I.ii.intro.2). The subsequent discussion continues this focus on the effects of the expressions of passion on spectators. At one level, this is unsurprising-what else have spectators to go on when assessing what agents are feeling? But on another level, as I will show below, this is problematic if it means that agents can secure the sympathy of the spectator by merely controlling the expressions of their emotions.

7. These scenes of self-command suggest that controlling the expressions of feeling is a way of controlling feeling itself. Elsewhere Smith 
suggests that the company of strangers who feel no partiality towards you can have the effect of helping you to become more tranquil by making you "assume" the appearance of tranquility (I.i.4.9-10).

8. Smith discusses the difference between hypocrisy and permissible dissimulation at III.5.1 and again at VI.iii.12. The crucial difference is in the motives for each. The hypocrite or blameworthy dissembler seeks to put on a false face because of a "selfish intention" or a special need for self-preservation. The permissible dissembler does so in order to achieve the sympathy of an impartial spectator.

9. Smith's discussion of the ways in which the "savage" is selfcommanded (V.2.9-11) is an extraordinary example of the descriptive techniques I will be discussing below. While telling the reader that the "savage" reveals absolutely no feeling, even to his closest neighbors and family members, Smith also narrates the furious and extreme degrees of feeling hiding beneath the countenance of serenity.

10. See Martha Nussbaum, “The 'Morality of Pity': Sophocles' Philoctetes," in Rethinking Tragedy, edited by Rita Felski (Johns Hopkins University Press, 2008), 148-169.

11. See Smith's footnote to I.iii.1.9, added in the second edition.

12. Another option is that spectators end up sympathizing with feigned emotions, but that agents are sincerely striving to feel the emotion they are presenting, and that in that attempt actually come to feel the proper emotion. Spectators would thus be proleptically sympathizing with the agent or sympathizing with the agent's better self. I do not have the space here to explore this possibility, and this is not the way Smith himself describes the sympathetic interaction, but it may be a promising way of reimagining Smithian spectatorship so as to avoid the problems I have found. See Fleischacker (2019), 34-41 for an interpretation of Smith that comes close to the possibility I have sketched here. And see Fleischacker (2012), 295-296 for a similar description of this problem of access to the "original passion" of the agent.

13. See I.i.5 for Smith's discussion of the difference between virtue, which involves the exertions of self-command, and "mere propriety," which does not. See also VI.iii, where Smith repeatedly emphasizes 
that the exertions of self-command add a "dazzle" or "lustre" to an agent's actions. If it is possible for the spectator to tell the virtuous action from the merely proper, then it must be possible for the spectator to tell when self-command is present. See Wendy Anne Lee, Failures of Feeling: Insensibility and the Novel (Stanford University Press, 2019) for an excellent and wider treatment of this problem.

14. Other traits that mask their own efforts include (potentially): strength of mind, modesty, humility, and composure. I explore some of these virtues, focusing on humility, in Lauren Kopajtic, "The Eyes of Others: Hume and Smith on Humility and Qualities of Reserve," in Humility: A History, edited by Justin Steinberg (Oxford University Press, forthcoming).

15. Another resource is one's own experience with concealing and commanding feeling. I know what it is like to conceal a feeling or to command a feeling, and I know that I can do so without other people picking up on what I am doing, so I infer that other people might be doing the same without my being aware that they are. This will not help the problem very much. This inference opens up the spectator's suite of interpretive possibilities, it does not help to decide an interpretation. Knowing that the agent I am observing might be concealing or feigning her feelings only serves to render my imaginative reconstruction of her situation less stable and determinate. This piece of information turns everyone into a potential dissembler. I thank Chris Florio for pressing me to further consider this possibility.

16. Griswold's comparison of Smith and Rousseau in several places has been extremely helpful to me in thinking through the tension between spectatorship and self-command in Smith. See Charles L. Griswold, Jean-Jacques Rousseau, and Adam Smith: A Philosophical Encounter (Routledge, 2018); "Being and Appearing: Selffalsification, Exchange and Freedom in Rousseau and Adam Smith," in Adam Smith and Rousseau: Ethics, Politics, Economics, edited by Maria Pia Paganelli, Denis C. Rasmussen, and Craig Smith (Edinburgh University Press, 2018); and "Smith and Rousseau in Dialogue: Sympathy, Pitié, Spectatorship and Narrative," in The Philosophy of Adam Smith, Volume 5 of the Adam Smith Review, 
edited by Vivienne Brown and Samuel Fleischacker (2010), 5984. For further discussion of Smithian sympathy and narrative, see also Stephanie Degooyer, "'The Eyes of Other People': Adam Smith's Triangular Sympathy and the Sentimental Novel," ELH, 85:3 (2018), 669-690.

17. See also Fleischacker (2019), 15 and 45-46, and Martha Nussbaum "Steerforth's Arm: Love and the Moral Point of View," in Love's Knowledge: Essays on Philosophy and Literature (Oxford University Press, 1990), 339 for similar points about spectatorship and readership.

18. My argument is thus connected to the question of the moral importance of literature, but I am not offering a general claim about how reading literature will make you a better person. My claim is that, in the context of Smith's moral philosophy, reading certain kinds of literature may help you to become a more skilled Smithian spectator. I am also not claiming that fictional literature alone is capable of contributing to this development. Other art forms (theater and dramatic arts especially come to mind) may provide similarly helpful training-grounds, but I cannot discuss these possibilities here. See Candace Vogler, "The Moral of the Story," Critical Inquiry, 34 (2007), 5-35 for a compelling set of concerns about the (mis-)uses of literature by moral philosophers, and see Peter Goldie, "How We Think of Others' Emotions," Mind \& Language, 14:4 (1999), 394423 , especially 417-418, for an excellent overview of the skills and capabilities required for imagining and understanding the emotions of others.

19. Smith's discussion of the character sketch tradition at VII.iv.3-6 also focuses on the instructive potential of description and illustration. And Smith's comments on the effects of narrative in the Lectures on Rhetoric and Belles Lettres, ed. J.C. Bryce (Liberty Fund, 1983) also suggest that he found novels and romances to be potentially instructive, although primarily entertaining (see Lectures 15-20 especially). Further exploration of how Smith might have understood the instructive potential of literature is needed, as is an examination of the specific authors he references. For further discussion of Smith's rhetoric and his engagement with literature, 
see Colin Heydt, "AA Delicate and Accurate Pencil': Adam Smith, Description, and Philosophy as Moral Education," in New Essays on Adam Smith's Moral Philosophy, edited by Wade L. Robison and David B. Suits (RIT Press, 2012), 211-227; Valihora (2010); Griswold (2010) and Adam Smith and the Virtues of Enlightenment (Cambridge University Press, 1999); Neven Leddy, "Adam Smith's Moral Philosophy in the Context of Eighteenth-Century French Fiction," The Adam Smith Review, 4 (2009), 158-180; and Deidre Dawson, "Is Sympathy so Surprising? Adam Smith and the French Fictions of Sympathy," Eighteenth Century Life, 15 (1991), 47-62. For comprehensive discussion of the reciprocal influence of philosophy and literature in the eighteenth-century, especially in Scotland and England, see John Mullan, Sentiment and Sensibility: The Language of Feeling in the Eighteenth Century (Oxford University Press, 1988); and John Dwyer, Virtuous Discourse: Sensibility and Community in Late Eighteenth-Century Scotland (John Donald Publishers, 1987).

20. This pretense of the sentimental, epistolary novel has been welldocumented and much discussed. For a classic treatment, see Ian Watt, The Rise of the Novel (University of California Press, 1959), 192-196.

21. I am not claiming that Richardson, Marivaux, or Riccoboni consciously conceived of themselves as developing such techniques, merely that their shared interest in minute depictions of the interior lives of their subjects, combined with an attempt to draw on the reader's sympathy, place them in the camp of novelists who were working to render the mind and heart of the other more transparent and accessible. See Joe Bray, "Letters," in Samuel Richardson in Context, edited by Peter Sabor and Betty A. Schellenberg (Cambridge University Press, 2017), 163-170, at 164-166. I thank Arden Hegele for this reference and for her helpful discussion of these points.

22. See Dorrit Cohn, Transparent Minds: Narrative Modes for Presenting Consciousness in Fiction (Princeton University Press, 1978) for a classic treatment of this topic. 
23. Greiner (2012) provides a recent discussion of how the novel (her focus is on the nineteenth-century novel) works with and through the reader's sympathetic capabilities. I have some reservations about Greiner's use of Smith's moral psychology throughout her book, but I agree with her general claim.

24. See Barbara Benedict, Framing Feeling: Sentiment and Style in English Prose Fiction 1745-1800 (AMS Press, 1994), 196-214.

25. I focus on Austen for several reasons: First, as mentioned in note 2 above, she was a near contemporary of Smith's and may have been familiar with his writings and ideas, at least in a diffuse form; second, Austen is widely considered to be the first master of free indirect style in the English literary tradition, and so provides the clearest, most compelling, and closest (to Smith) examples of the techniques I am focusing on; and third, her novels are well-known in the present day and so make her an easier novelist to use than, say, Riccoboni.

26. Jane Austen, Sense and Sensibility, ed. Edward Copeland, The Cambridge Edition of the Works of Jane Austen, gen. ed. Janet Todd (Cambridge University Press, 2013). Hereafter, references to Sense and Sensibility will be abbreviated as (SS).

27. See Tony Tanner, Jane Austen (Palgrave Macmillan, 2007); Jenny Davidson, Hypocrisy and the Politics of Politeness: Manners and Morals from Locke to Austen (Cambridge University Press, 2004); and Patricia Spacks, Privacy: Concealing the Eighteenth-Century Self (University of Chicago Press, 2003) for further discussion of Elinor's self-command as verging on hypocrisy, dissimulation, and other forms of deception.

28. If this degree of secrecy and concealment is possible in a virtuous person like Elinor, consider what is possible for a committed deceiver like Mr. Eliot of Austen's Persuasion, or Lovelace of Richardson's Clarissa. At one point, Lovelace brags to his correspondent that Clarissa would never "discover some emotion" in him to clue her in to his plans, for it "lay deeper than her eye could reach, though it had been a sunbeam" [Samuel Richardson, Clarissa, or The History of a Young Lady, ed. Angus Ross (Penguin Books, 2004), 472]. 
29. Jane Fairfax, like Elinor, is keeping a secret throughout most of the novel, and she, like Elinor, is a master at controlling her emotions. But we see Jane almost entirely from the perspective of Emma Woodhouse and other characters who find her to be cold and reserved. Without the interior view afforded through techniques like focalization and free indirect discourse, we can only see Jane, with Emma, as "disgustingly, ... suspiciously reserved." See, e.g., Jane Austen, Emma, eds. Richard Cronin and Dorothy McMillan, The Cambridge Edition of the Works of Jane Austen, gen. ed. Janet Todd (Cambridge University Press, 2013), 178-181, 218-219, 311-312.

30. There is a vast amount of literature on Austen's narrative techniques and I cannot engage with it here. For an entry into the literature, see Jane Spencer, "Narrative Technique: Austen and Her Contemporaries," in A Companion to Jane Austen, edited by Claudia L. Johnson and Clara Tuite (Wiley-Blackwell, 2009), 185-194.

31. I do not want to overstate the centrality of these illustrations in Smith's TMS. As Griswold has argued, the overwhelmingly theoretical and analytical discursive style of TMS "tends to occlude" the narratival and illustrative dimensions $(2010,73)$.

32. I am grateful to the Society of Fellows and the Heyman Center for the Humanities at Columbia University for support while this chapter was written. And I am grateful to Daniel Moerner, Matt Leisinger, Sean Greenberg, and Kathy Lubey for invitations that enabled me to develop the chapter. It has benefitted greatly from conversation with audiences at several different workshops: the SEMPY series at Yale, the NY/NJ Workshop in Early Modern Philosophy, the Scientia workshop at UC Irvine, the Virtue Ethics and Moral Psychology working group in NYC, and the Columbia Faculty Seminar in Eighteenth-Century European Culture. I am especially grateful to Lanier Anderson, Stephen Darwall, Chris Florio, Eileen Gillooly, Robert Gooding-Williams, Sean Greenberg, Arden Hegele, Wendy Anne Lee, Reinhold Martin, Justin Steinberg, and several anonymous referees for their pointed questions and helpful suggestions. 